\title{
Understanding where parents take their sick children and why it matters: a multi-country analysis
}

\author{
Stephen Hodgins, ${ }^{\text {a }}$ Thomas Pullum, ${ }^{\text {beanne Dougherty }}{ }^{c}$
}

To effectively reach children with potentially life-threatening illness with needed treatment, it is important to understand where parents seek care. Data from 42 DHS and MICS surveys conducted since 2005 show that a majority of care in Africa is sought from the public sector; in South Asia, from the private sector; and in Southeast Asia, from a public-private mix. We recommend that such data be made available in standard DHS and MICS reports.

\section{ABSTRACT}

Background: Developing effective context-specific strategies to ensure that a high proportion of children receive timely and appropriate care requires knowing the source from which care is sought. Although Demographic and Health Surveys (DHS) and Multiple Indicator Cluster Surveys (MICS) collect such data in disaggregated form, they are not made available in the standard DHS and MICS reports.

Methods: Secondary data analysis was done on 42 DHS and MICS surveys conducted since 2005 for care seeking for acute respiratory illness (DHS and MICS), diarrhea (DHS only), and fever (DHS only), disaggregating by urban-rural settings. Eight categories were used for source of care. Stata, version 12, was used for the analysis.

Results: Patterns varied considerably, with care seeking in most of sub-Saharan Africa predominantly from public-sector providers, in South Asia predominantly from the private sector, and in Southeast Asia from a mix of public and private sources. Community health workers were not an important source of care.

Conclusions: Variation in care-seeking patterns has implications for effective strategy, as described in more detail in 5 country examples from Asia and Africa. The analysis also suggests that it may be inappropriate to focus program efforts on community health workers to the exclusion of more widely used sources of care. The authors argue that, in order to ensure sounder program approaches, disaggregated care-seeking data should be routinely included in DHS and MICS reports. Finally, the authors call for more data on actual care provided in order to improve quality of care.

\section{BACKGROUND}

I $\mathrm{n}$ less-developed countries, pneumonia and diarrhea remain the leading causes of deaths among children beyond the newborn period; in many sub-Saharan African countries (particularly in West Africa), they are joined by malaria as a major cause. ${ }^{1}$ Preventive interventions are available for each of these conditions, but timely and appropriate treatment remains a fundamentally important program element. The key first steps in its successful delivery are recognition by the caregiver and care seeking outside the home.

\footnotetext{
"Save the Children, Washington, DC, USA

${ }^{b}$ ICF International, Calverton, MD, USA

'John Snow, Inc., Washington, DC, USA

Correspondence to Stephen Hodgins (shodgins@savechildren.org).
}

In order to develop child survival strategies that effectively address the need for treatment of potentially life-threatening childhood illness, program managers need to understand the populations they work with. Indeed, it is to those developing and managing child health programs, particularly at the country level, that this paper is primarily directed. They need answers to key questions:

- To what extent are caregivers recognizing illness and seeking outside care?

- When they do seek outside care, where do they go?

- When care is sought, what actual treatments are received?

With such information, program managers are better enabled to develop strategies that respond to the challenges of their specific settings. 
The Demographic and Health Surveys (DHS) and Multiple Indicator Cluster Surveys (MICS) have long included questions on child illness and care seeking. Questions are asked to elicit a recent history of cough, fever, and diarrhea. For each of these 3 categories of illness, the caregiver is then asked if advice or treatment was sought outside the home and, if so, from what source. In standard DHS reports, the one way this information is used is to generate an indicator for "care seeking from an appropriate provider." The numerator for this indicator consists of cases for which advice or treatment was sought from a category of provider considered able to provide competent care (health facility or professional health worker). However, although the DHS (and MICS) data sets include details on specific sources of care, this is not presented in the standard reports. This is unfortunate because such information is needed to develop strategies that respond to the actual situation on the ground, with respect to current source of care.

This paper reports on a secondary analysis of standard DHS surveys conducted in sub-Saharan Africa, South Asia, and Southeast Asia since 2005-2006 (excluding small-population island nations), and of MICS surveys conducted over the period 2005-2008, providing a disaggregated picture of care seeking for cough, fever, and diarrhea.

\section{METHODS}

The data come from surveys conducted by Measure DHS, a project of the Bureau for Global Health at the U.S. Agency for International Development (USAID), and by the United Nations Children's Fund (UNICEF). All of the data sets are available online (at www. measuredhs.com and www.childinfo.org), along with country reports that include basic analyses of child health data, the questionnaires, and other documentation.

Information about treatment for possible acute respiratory infection (as this is operationalized in DHS and MICS studies) was reported for an average of 695 children in 24 DHS surveys, a total of 16,682 children, and in an additional 13 MICS surveys (with an average of 288 children for a total of 5,878 children). Fever was reported for an average of 2,295 children from 29 DHS surveys, a total of 66,549 cases. Information on diarrhea comes from the same 29 surveys, with an average of 1,369 children under 5 reporting diarrhea symptoms in the past 2 weeks in each of the surveys, giving a total of 39,393 cases.
Although advice or treatment-seeking questions were equivalent in the 2 survey types for acute respiratory infection (ARI), they were not for diarrhea and fever. MICS questions did not ask where the mothers sought advice or treatment, and questions focused instead on sources for specific treatments. For diarrhea, the MICS asked, "Where did you get the ORS [oral rehydration salts] packet?" For fever, the survey asked, "Where did you get the anti-malarials?" Because of this lack of comparability with the DHS questions, analysis on care seeking for diarrhea and fever was done using only DHS data.

The structure of the portion of the questionnaire on care seeking was essentially the same in all surveys (for ARI, in both DHS and MICS, and for diarrhea and fever in DHS). The options for place of treatment were similar but not identical: in each of the surveys, specific types of health facility or provider, both formal and informal, thought to provide at least some sick-child care in that country setting were included as possible response categories. Because these categories varied across surveys, for our purposes it was necessary to form a set of general categories to which these responses could be mapped:

- Public-sector hospital

- Public-sector peripheral health facility (nonhospital), including mobile/outreach clinics

- Private-sector health professionals, clinics, and hospitals

- Community health workers

- Services provided by faith-based organizations and other NGOs

- Retail outlets (only), including pharmacies, patent medicine shops, vendors

- Non-allopathic providers

We also included an "other" category for responses that did not fit in any of the above, and we created a new variable for "any public provider," which included cases for which care was sought from one of the first 2 categories above. Note that with the exception of retail outlets, the categories used were not mutually exclusive so if, for the same case, advice or treatment was sought from providers from more than 1 category, that case would contribute to both values. Retail outlets were treated differently because we wanted to focus on episodes for which advice or treatment was sought from such outlets alone and so did not include those in

\author{
Child health \\ program \\ managers need \\ answers to key \\ questions about \\ care seeking in \\ order to respond \\ effectively to the \\ challenges of their \\ specific settings.
}


which the shop simply filled a prescription based on advice received from another category of provider.

Because the survey question is administered in a way that can elicit more than 1 source of care per episode, if, in fact, more than 1 was consulted, summing the proportions across all sources in most cases yields a slightly larger number than the total proportion of cases for which care was sought.

Although the interviewers were instructed to probe and include multiple sources, it is likely that there was some variation from one interviewer to another, as well as from one survey to another, in the extent to which multiple sources were identified.

Note that all n's and percentages in the tables are weighted. DHS and MICS surveys use a stratified cluster design, typically with strata consisting of all combinations of region (the first subnational unit) and place of residence (urban/ rural). The weighting procedures are built into the software package used. Programming was done primarily with version 12 of Stata.

Supplementing the analysis disaggregating by type of provider, we have further explored aspects of care rendered by different categories of provider for insights into quality or appropriateness. For ARI, in DHS surveys that asked both about source of care and whether antibiotics were dispensed, we determined the proportion of cases receiving antibiotics, disaggregating by "appropriate" or "medically trained" providers (government health facilities, NGO health facilities, private physicians or health facilities, community health workers) vs. "non-appropriate" providers (drugs shops or pharmacies only and non-allopathic providers). In DHS, the ARI category is used as a reasonable proxy for possible pneumonia, potentially warranting antibiotic treatment. As such, the proportion of such cases for which antibiotics are given is a commonly used population indicator for adequacy of reach of pneumonia treatment services. Certainly, some proportion of such cases would not have had symptoms or signs at the time of examination that should prompt a competent clinician to prescribe antibiotics; however, very low rates of antibiotic treatment among cases seen by a health worker would suggest a systemic problem with adequacy of care.

For diarrhea care, we looked at 2 measures of quality. First, we determined the proportion receiving ORS, disaggregating by "appropriate" vs. "non-appropriate" provider. Second, restricting to cases of reported non-bloody diarrhea, we determined the proportion reporting using pills or syrups (excluding zinc). In most settings, these would include antibiotics and anti-motility agents, although, of course, this category could include many other remedies. We did not include cases of bloody diarrhea, for which antibiotic treatment would be warranted (and a response indicating use of pills or syrups could represent appropriate care). For the retained non-bloody diarrhea cases, current treatment recommended by the World Health Organization (WHO) includes only zinc and ORS. Therefore, we interpret the dispensing of other products for non-bloody diarrhea as representing a sub-optimal practice.

\section{RESULTS}

\section{Overview}

Detailed results for source of care for ARI, fever, and diarrhea are presented in Table 1, Table 2, and Table 3, and for quality of ARI and diarrhea care in Table 4 and Table 5. The map (see Figure) provides a clearer spatial picture of similarities and differences across countries and regions. As is evident from the map, a pattern of reliance primarily on public-sector sources is predominant across Africa, with several notable exceptions (Nigeria, Somalia, and Uganda). In South Asia, by contrast, the private sector is the major source. In Southeast Asia there is a more mixed pattern for sources of care. In general, care-seeking levels were high in the Asian countries (with the exception of the Philippines and the 2 Central Asian Republics included in the analysis), and mortality was lower than in the African countries.

\section{Acute Respiratory Infection Care-Seeking Levels}

For ARI, in 31 of the 42 countries for which data are presented here, care is sought from any source for at least $60 \%$ of reported cases. In 8 countries (Burundi, Central African Republic, Lao People's Democratic Republic, Madagascar, Mali, Mauritania, Sierra Leone, Zimbabwe), care seeking is somewhat lower, in the range of $40 \%-59 \%$. Care seeking is much lower in 3 countries (Ethiopia, Somalia, and Togo), at around $30 \%$. In most of the countries considered here, a relatively small proportion of care is sought from categories of source assumed to not be medically qualified (shops and non-allopathic providers). But in 9 of these countries, more than 30\% of care is sought from such sources. Six of these countries 


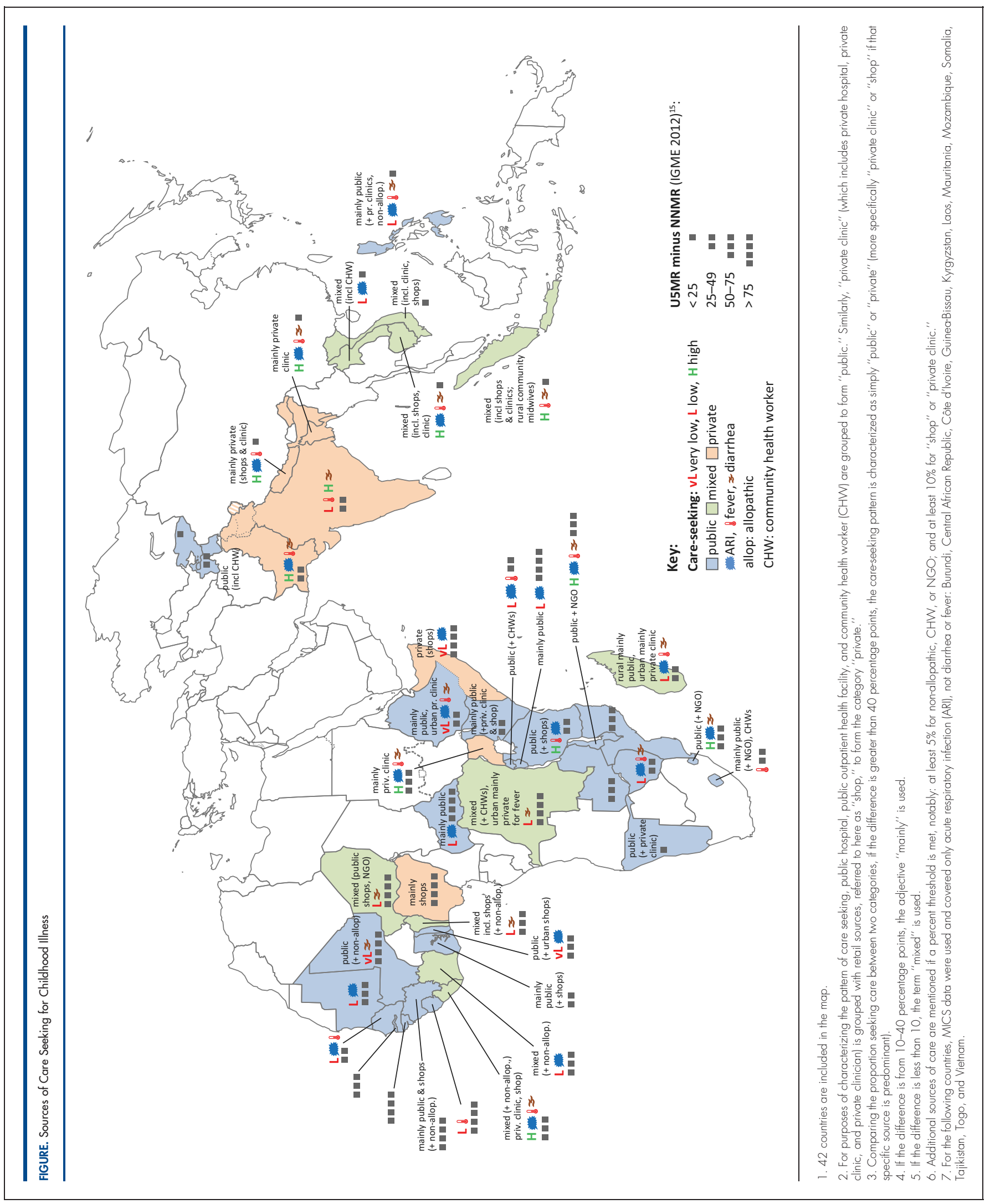


are in western and west-central Africa (Benin, Côte d'Ivoire, the Democratic Republic of Congo, Mali, Niger, and Nigeria; the others were Bangladesh, Nepal, and Somalia).

\section{Asia}

The specific categories of provider from which care is obtained vary considerably by country, but certain patterns are evident. This is best appreciated by referring to the map (see Figure). In the Asian countries included here, care is obtained predominantly from the private sector, except in the 2 Central Asian Republics and Vietnam (where the public sector is the primary source); and in the Philippines, which has a mixed, public-private picture. In most of those countries where the private sector predominates, private clinicians are reported as the main source, although in Indonesia, drug shops were equally important, and in Nepal they were the most widely used source. The one Asian country included here in which community health workers (CHWs) are a significant source of care (for purposes of this paper, "significant" is used for cases in which 10\% or more of cases sought care from a particular source) was Indonesia, where care was sought from village "health cadres" for $12 \%$ of cases.

\section{The public sector plays a more important role as a provider of ARI care in Africa than in Asia.}

\section{Africa}

In general, the public sector plays a more important role as a provider of ARI care in Africa than in Asia. But this is by no means the case in all countries. In 6 of the 16 western and west-central African countries included, more cases were treated outside than inside the public sector, with the private sector accounting for a particularly high proportion in the Democratic Republic of Congo, Niger, and Nigeria (the other countries in this region with predominantly private provision were Benin, Côte d'Ivoire, and Guinea). Among these countries, private-sector care consists mainly of care from shops, with the exception being the Democratic Republic of Congo, where private clinicians are also an important source. In several countries in this region, non-allopathic providers are an important source (Benin, Côte d'Ivoire, Guinea, and Mali). In several other countries where the public sector accounts for the largest proportion, private providers are also an important source, notably in Ghana and Liberia. In no countries in this region were CHWs a significant source of care (at least at the time of the most recent surveys), including Senegal, which was one of the first countries in Africa to scale up "community case management" (CCM). In southern and eastern Africa, in general, the public sector is the most important source for ARI care, but the picture varies across countries. In Kenya and Tanzania, although the public sector is the major source, drug shops are also important. Similarly, while the public sector is the major source in Madagascar and Namibia, private clinicians are also an important source. Uganda and Somalia are the 2 countries in this region considered in this analysis where the private sector is the main source of ARI care, with private clinicians providing care in Uganda, and shops filling that role in Somalia. Rwanda is the one country in this region where CHWs were a significant source of care at the time of the most recent survey (they were not in Madagascar or Malawi, where CCM has recently been widely implemented).

\section{"Appropriate" vs. "Non-Appropriate" Care}

For a small number of the surveys, we also had access to information on receipt of antibiotics, which is presented here disaggregated by "appropriate" vs. "non-appropriate" categories of provider (Table 4). Among those seeking care for ARI from medically qualified health workers, the proportion reporting receiving antibiotics varied considerably, with only $21 \%$ of such cases receiving antibiotics in Swaziland vs. $83 \%$ in Bangladesh. Among this small set of countries, only in Bangladesh and Nepal did "non-appropriate" providers constitute a significant source of care for ARI. Somewhat surprisingly, in Nepal, cases seen by such providers were far more likely to be treated with antibiotics than those seen by "appropriate" providers. In this instance, "non-appropriate" providers consisted primarily of drug shops and, as other investigators have documented, ${ }^{5}$ most cases treated in this subsector were in fact assessed at the "shop" by some category of health worker.

\section{Urban-Rural Disparities}

For care seeking for ARI, in most countries there were moderate urban-rural disparities $(5 \%-10 \%$ lower level of care seeking from any source, in rural areas); however, in 5 of the countries included here, the disparity was greater than 20\% (Ethiopia, Guinea-Bissau, Lao, Rwanda, and Somalia), and in 8 countries care seeking was approximately equally common in rural and urban areas (the Gambia, Ghana, Indonesia, Mozambique, the Philippines, Tajikistan, Togo, 
and Zambia). In most countries, private sources were more important in urban than in rural areas.

\section{Fever}

\section{Care-Seeking Levels}

As a symptom of childhood illness, fever is of particular public health significance in countries with more heavily endemic malaria. Among the countries for which data were analyzed for this paper, care seeking for fever, from any source, was at similar levels as for ARI (Table 2). In 20 of the 29 countries, $60 \%$ or more of cases sought care. In 8 countries (India, Madagascar, Mali, the Philippines, Rwanda, Senegal, Sierra Leone, and Zimbabwe), 40\%-59\% sought care. In Ethiopia, a much lower proportion (26\%) sought carealthough malaria is not a major public health problem in most of Ethiopia. The relatively low level of care seeking is of particular concern in those countries where malaria makes up a significant proportion of childhood deaths, notably Mali, Senegal, and Sierra Leone. As with ARI, in most countries non-medically qualified providers accounted for a small proportion of care. In 3 countries, however, they made up 30\%-50\% (Benin, Guinea, and Nigeria), and in Bangladesh (where malaria is not a significant public health problem) such providers accounted for over $60 \%$ of care. Categories of provider consulted were similar to those seen for ARI.

\section{Asia}

Among the Asian countries included, only in the Philippines was the public sector the principal source of care. Private clinicians were the main source of care in India and Pakistan. Bangladesh, Cambodia, and Nepal showed mixed pictures, with shops and private clinicians contributing. Non-allopathic providers were an important source in Bangladesh. Only in Indonesia were CHWs ("village health cadres") a significant source.

\section{Africa}

In 6 of the 10 western and west-central African countries, the private sector was the main source of care for fever. In Liberia, clinicians were the main private source; in the Democratic Republic of Congo, shops and private clinicians were equally important. In the others (Benin, Guinea, Niger, and Nigeria), private shops/vendors predominated. Non-allopathic providers were a significant source in Benin, Guinea, and Mali. In the remaining countries in this region, the public sector was the main source, with contributions from the private sector. NGO/religious sources were an important contributor in Niger. CHWs were not a significant source in any of these countries.

In southern and eastern Africa, the picture was similar to that for ARI. The public sector accounted for the largest proportion of cases seen except in Uganda, where private clinicians predominated. Drug shops were an important source in Kenya and Tanzania, as were CHWs in Rwanda. Religious/NGO institutions were a significant source in Lesotho and Swaziland.

\section{Urban-Rural Disparities}

Urban-rural disparities for fever differed from those seen with ARI; many countries (12) had essentially equally high care-seeking rates in urban and rural areas. Only l (Sierra Leone) had a gap of more than 20 percentage points. As with ARI, the private sector was generally a more important source in urban settings than in rural ones.

\section{Diarrhea}

\section{Care-Seeking Levels}

Although in most countries care for diarrhea (Table 3) was sought outside the home for most cases, such care seeking was less frequent than for ARI or fever. In 10 of 29 countries considered here, less than half of cases received care outside the home. This included several western and west-central African countries that were also noted to have lower levels of care seeking for ARI or fever, notably the Democratic Republic of Congo, Guinea, Mali, Niger, Nigeria, and Senegal. Other countries where less than half received such care were Ethiopia, Madagascar, the Philippines, and Zimbabwe. Non-medically qualified providers accounted for $30 \%-50 \%$ of cases in many of the western African countries (Benin, Ghana, Guinea, Liberia, Mali, Niger, and Nigeria) as well as in Bangladesh and Nepal.

Bangladesh had the highest proportion of cases treated with ORS. However, the other countries with high ORS use (Kenya, Malawi, Namibia, and Sierra Leone) relied relatively little on non-medically trained providers. Community health workers were a significant source of diarrhea care in the Democratic Republic of

\section{Low levels of care seeking for fever is of particular concern in countries where malaria makes up a significant proportion of childhood deaths.}


Congo and Rwanda. ORS use was especially low $(<25 \%)$ in Madagascar, Mali, Senegal, and Zimbabwe where most diarrhea treatment is done in the public sector; in Niger, with mixed provision; and in Benin, where most such care is in the private sector.

\section{"Appropriate" vs. "Non-Appropriate" Care} Two dimensions of appropriateness or quality of diarrhea care were investigated (Table 5):

- The dispensing of pills and syrups other than zinc for non-bloody diarrhea (most often antibiotics or anti-motility drugs), which is not in compliance with WHO guidelines

- The use of ORS for all diarrhea cases as a positive indicator of quality

In 18 of 22 countries, most episodes of nonbloody diarrhea cared for by "appropriate," presumably medically qualified, providers received pills or syrups. Liberia and Namibia performed relatively better; only about one-third of such cases were given such non-recommended treatment.

On a more positive note, in the same number of countries (18 of 22) most "appropriate" providers dispensed ORS. A very high proportion dispensed ORS in Kenya, Namibia, Sierra Leone, and Zambia. In India, however, of cases seen by "appropriate" providers, only 36\% received ORS (in Madagascar, Senegal, and Zimbabwe; also, most cases seen by "appropriate" providers did not receive ORS).

Among "non-appropriate" sources, rates of provision of pills and syrups were similar to those for medically qualified providers. However, "non-appropriate" providers generally offered ORS much less frequently than did the medically qualified ones. In several countries, notably in Kenya, the Philippines, and Uganda, reported ORS-use rates were higher than care-seeking rates, possibly reflecting household management with ORS supplies regularly kept on hand.

\section{Urban-Rural Disparities}

Urban-rural disparities in care seeking were smaller for diarrhea than for the other 2 conditions, with 14 countries having essentially equal rates, and 2 (Malawi and Zimbabwe) having higher care seeking in rural than urban areas. Only Ethiopia had an urban-rural gap of greater than 20 percentage points. As with the other conditions, the usual pattern was greater use of private sources in urban than in rural areas.

\section{DISCUSSION AND CONCLUSIONS}

\section{Why This Analysis}

Other investigators have done similar analyses in the past, looking at care seeking in individual countries $^{2-5}$ and based on multi-country analysis of DHS data. ${ }^{6}$ In unpublished work, Montagu and Visconi ${ }^{7}$ have recently done such analysis looking specifically at care seeking from the public sector vs. private sector (further subdivided as formal vs. informal), disaggregating by wealth quintile. Their analysis, while useful in exploring policy-relevant equity issues, provides less immediately useful information for program managers interested in developing a contextually strategic approach to improving care among the populations they are serving.

There are limitations to the analysis presented in this paper. As is evident in the tables, for some of the surveys the samples are quite small; therefore, the point estimates lack statistical precision (this has been flagged by giving estimates based on a cell size of less than 25 in parentheses). The oldest of the surveys included date to 2005 and 2006, so for some countries the data presented here may not adequately represent the current situation. It is likely that in some surveys there is substantial misclassification. For example, the provider in a peripheral dispensary or health hut may be a cadre of community health worker or health auxiliary but cannot be identified as such through the currently available data. Likewise, in some settings ${ }^{5}$ the shops that caregivers report getting treatment from are, in effect, outpatient clinics where children are typically examined and the treatment decision is made by the health worker at the "shop," not by the household caregiver. Nevertheless, these disaggregated survey findings provide additional useful information to the program developer, over and above what is routinely presented in DHS and MICS survey reports. The 5 country boxes give examples of how these data can help guide program strategy and prioritization.

\section{Why Care-Seeking Patterns Are Important}

Current patterns of care seeking need to be an important consideration in the development of effective approaches to improve case management for childhood illness at population scale. For 
example, in a given setting, if seeking care from any source is particularly uncommon in rural areas, strategies should be developed to address the actual barriers to such care seeking-for example, task shifting case management to auxiliary health workers to bring services closer to the population. If there is a high rate of care seeking from private practitioners, it may be appropriate to investigate quality of care, as has been done in some studies, ${ }^{8}$ and, if serious problems are found, to develop strategies targeting quality of care in the private sector. Likewise, if shops are a major source of care, social marketing or social-franchising approaches could be appropriate to help ensure appropriateness of care.

We are fortunate that DHS and MICS data sets already include useful information on this issue. Every time this information has been needed at country level, however, it has required further secondary analysis. In this paper, we have addressed this gap, making such information available for program managers across this set of 42 countries (indeed, this is the main objective of this study). We believe that similar disaggregated analysis should be routinely included in subsequent DHS and MICS reports.

\section{Need to Know More About Actual Care Provided}

Although this analysis provides useful additional understanding of care-seeking patterns, clearly more is required to inform the development of strategies that are optimally responsive to the local context. Beyond knowing where caregivers are seeking treatment or advice, we need more information on the actual care provided. This paper has made available further analysis using DHS data from a limited number of countries, giving some indication about the quality of care provided, disaggregating by sources of care considered "appropriate" or "non-appropriate." In certain settings, patients may be obtaining suitable care from "non-appropriate" or informal providers-for example, receiving ORS for diarrhea. Programmatic use of such a distribution channel may well be appropriate in some settings. However, this analysis has also demonstrated that even "appropriate" providers may be giving substandard treatment. For example, in almost all of the surveys it was found that most such providers dispense pills and syrups of various kinds (other than zinc) for non-bloody diarrhea. Whereas, in Bangladesh, fully $77 \%$ of those going to "non-appropriate" providers (shops and non-allopathic practitioners) received ORS, in India, only $36 \%$ of cases seen by "appropriate" or medically qualified providers received ORS. In Swaziland, relatively few cases of ARI seen by "appropriate" providers received antibiotics. This kind of country-specific information is needed by those tasked with determining the most effective strategies for improving sick-child care in their settings.

\section{The Role of Community Health Workers}

Current global health program efforts in sickchild care focus mostly on "community case management," that is, care provided by community health workers or health auxiliaries. In the analysis presented in this paper, care given by such providers represents a very small part of the service delivery mix. The Democratic Republic of Congo and Rwanda were the only countries of those analyzed where over $10 \%$ of cases of diarrhea were treated by CHWs. Only in Indonesia and Rwanda did CHWs treat more than $10 \%$ of ARI cases. In Nepal, where use of CHWs for such case management was pioneered and first taken to national scale, only $2 \%-3 \%$ of ARI and diarrhea cases are seen by CHWs, and most care is provided in the private sector. In Senegal, where CCM had expanded to cover almost all districts in the country by the time of the most recent DHS, CHWs were seen for only $1 \%-2 \%$ of cases of the 3 conditions. In Malawi, there has recently been significant CCM program expansion, but the last DHS predated this, so it does not reflect whatever relative contribution this program may currently be making. Nevertheless, the analysis presented here suggests that in most settings it may be inappropriate to focus program efforts on CHWs to the exclusion of other sources of care, which may, in fact, be much more widely used.

\section{Context Matters}

As with most public health problems, context matters in care seeking for childhood illness. Strategies that fail to take context into account are likely to be less effective. The first step in developing a strategy that is responsive to the actual situation on the ground is to understand what that situation is. In this case, that means understanding where caregivers are going when their children fall ill and what care is actually provided.

\section{Disaggregated analysis of care-seeking behavior for child illness should be routinely included in DHS and MICS reports.}




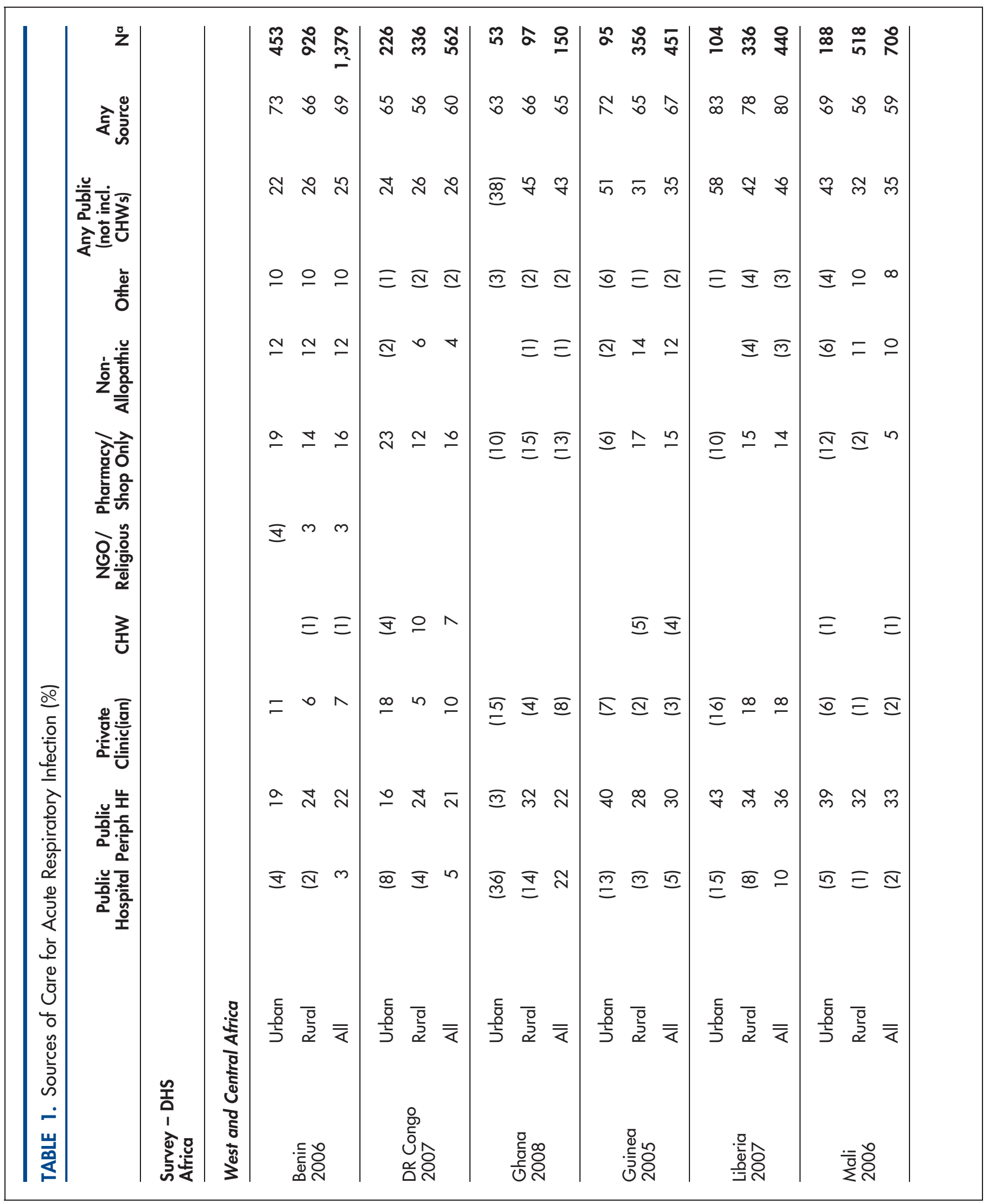




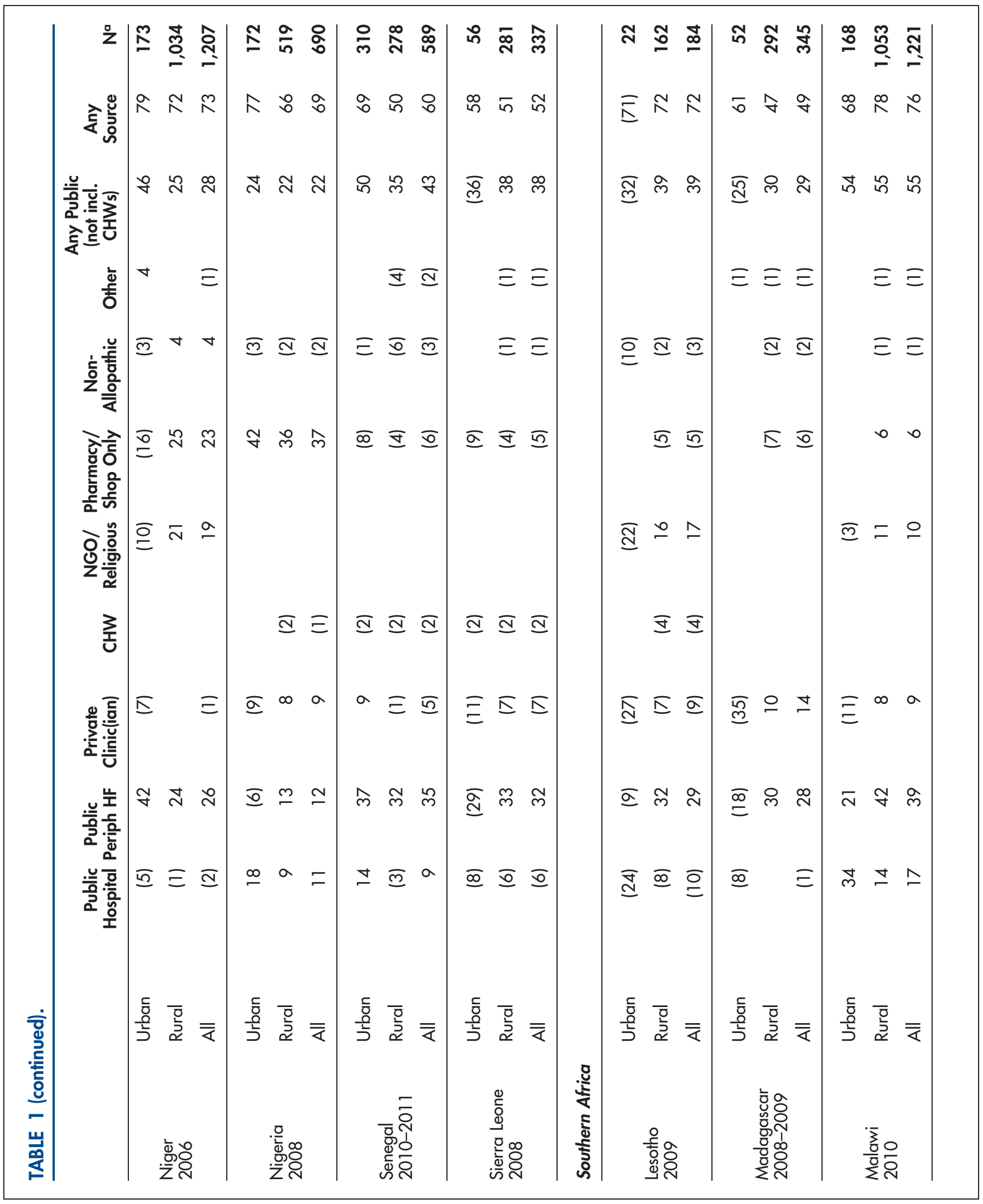




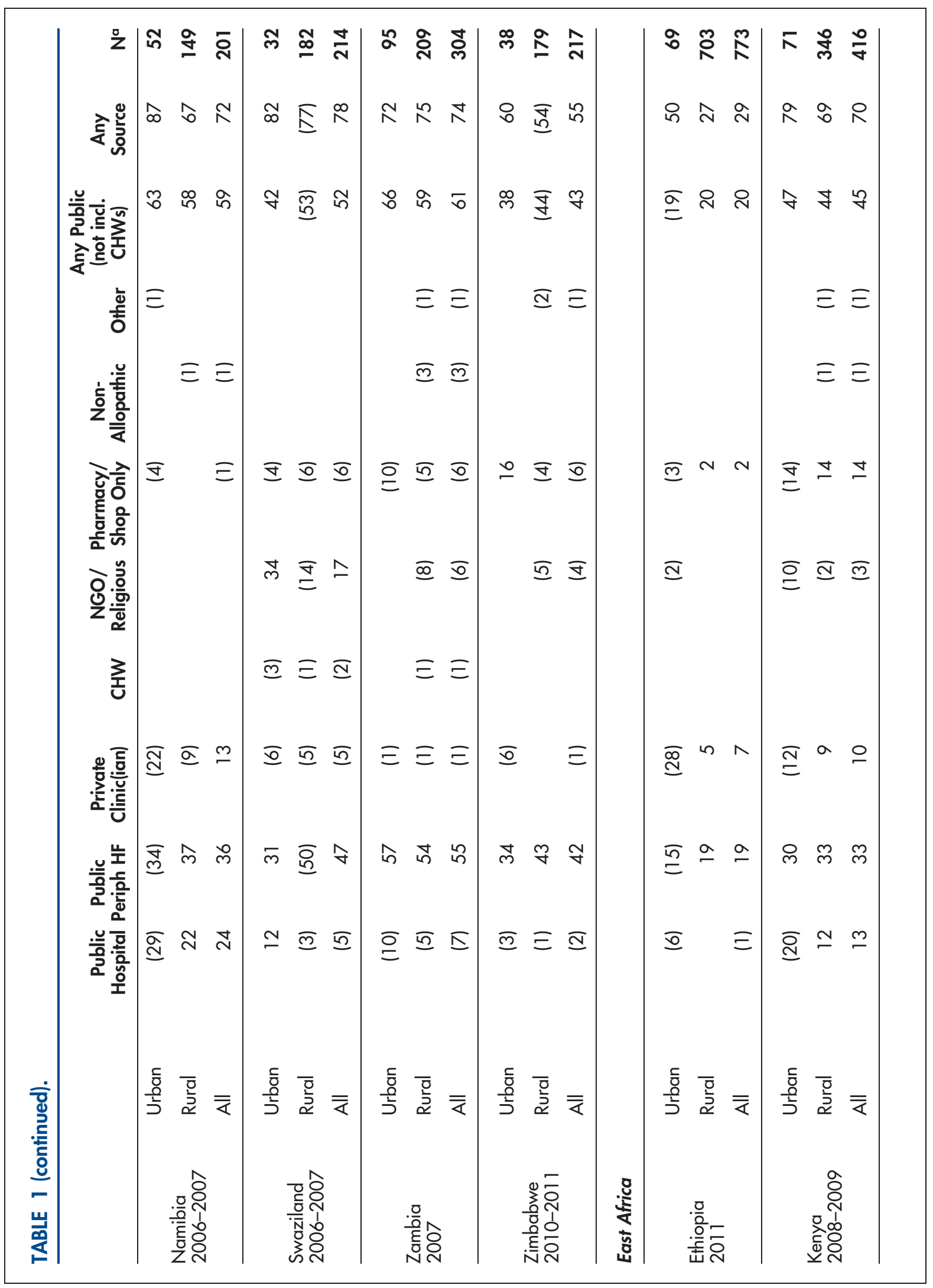




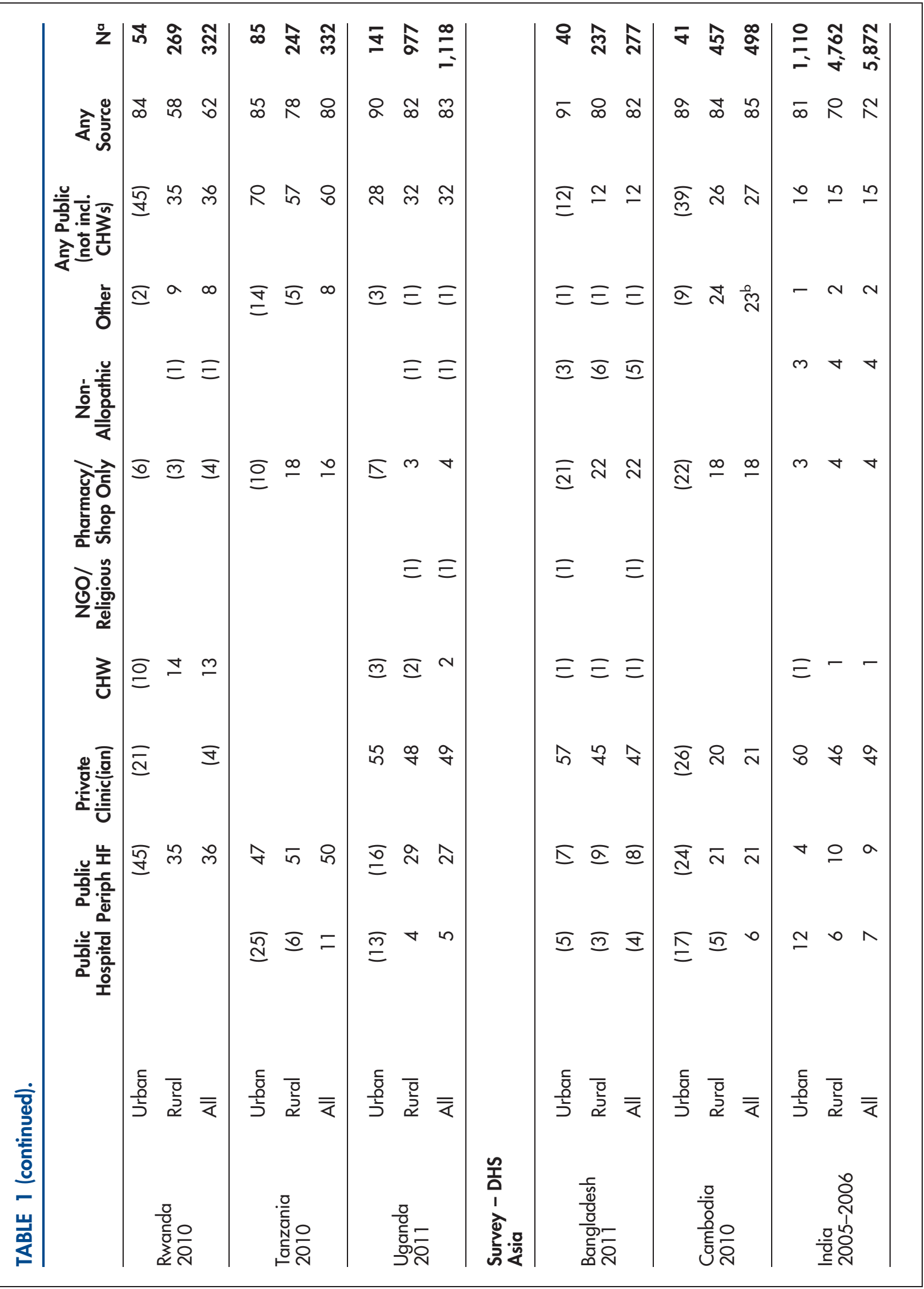




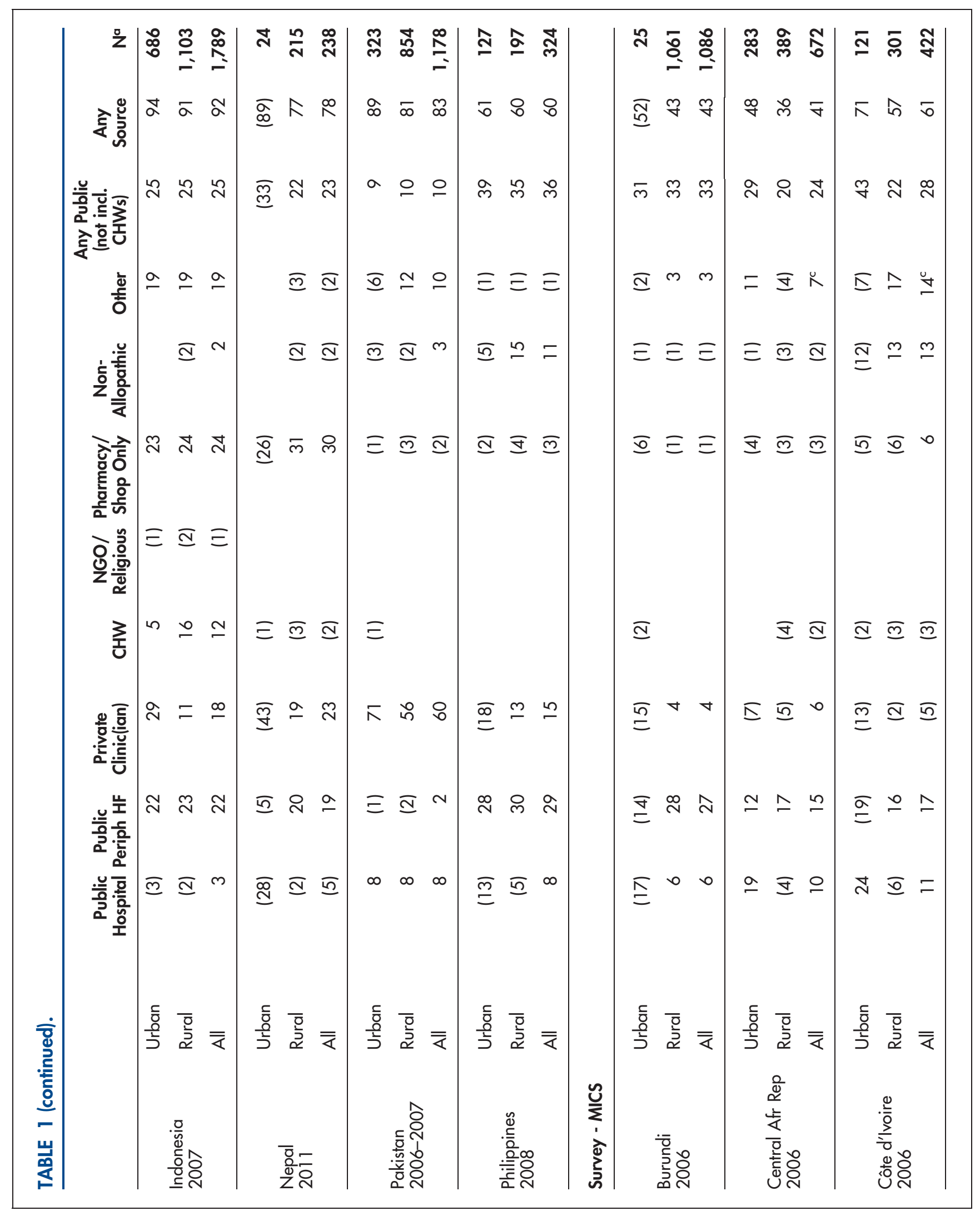




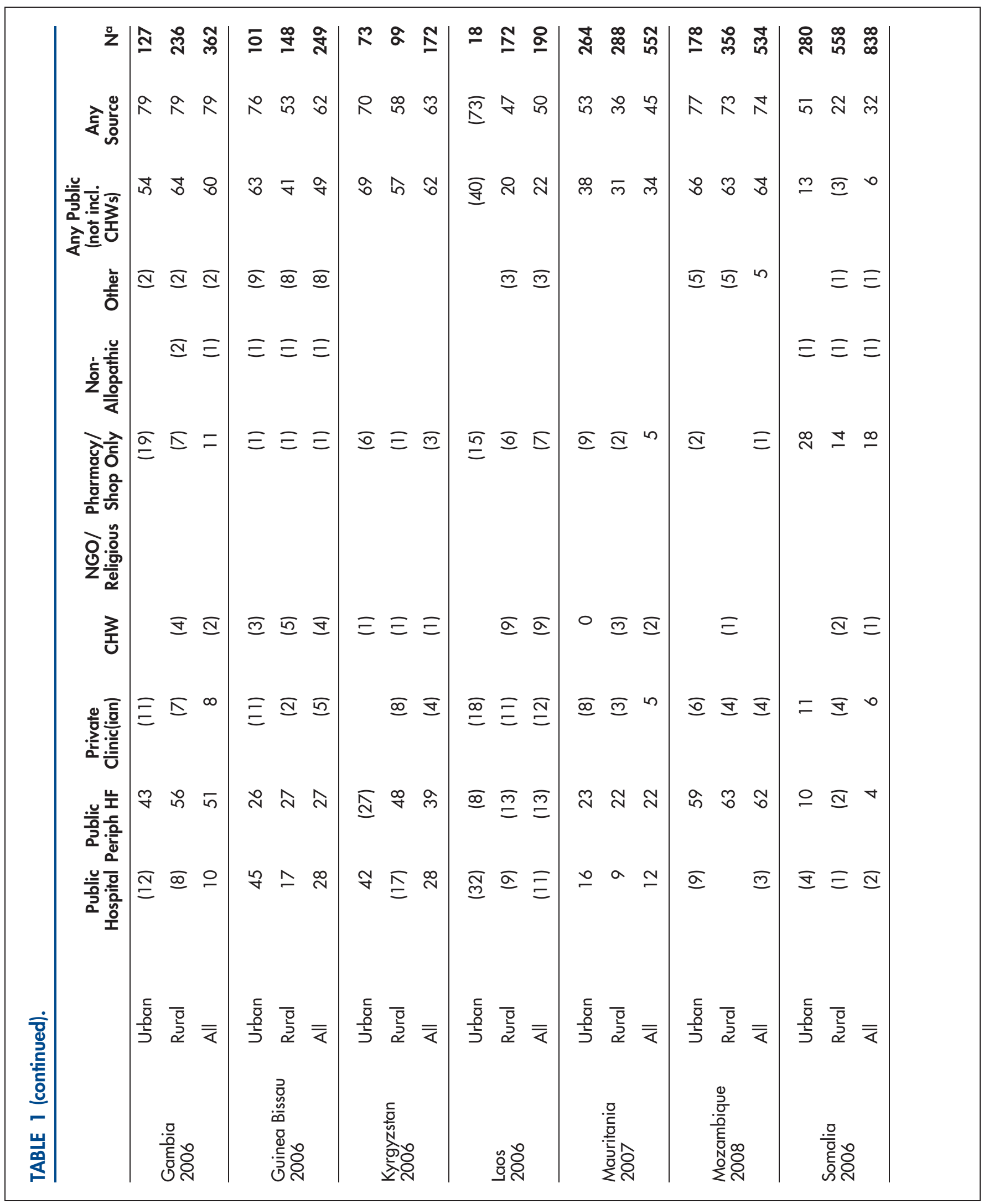




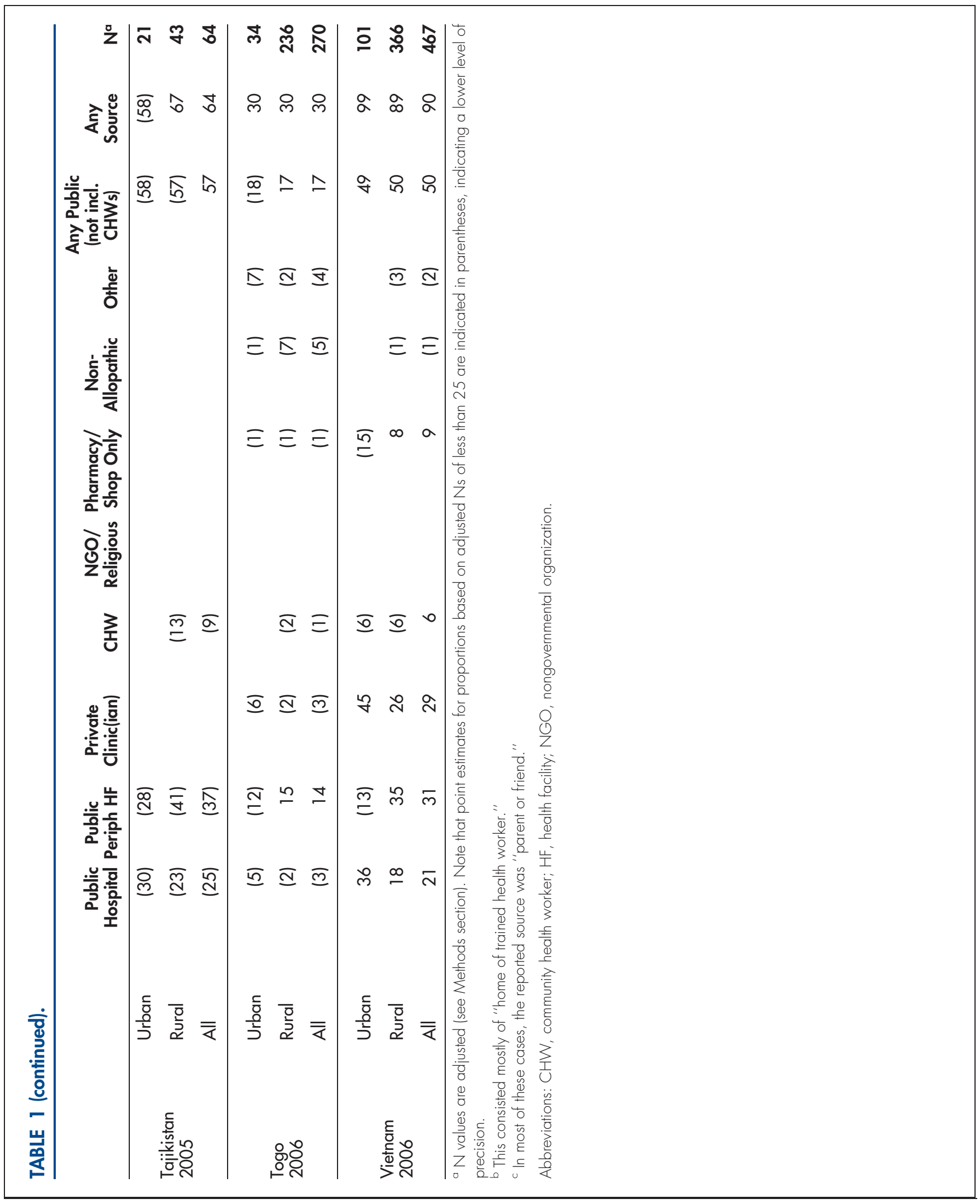




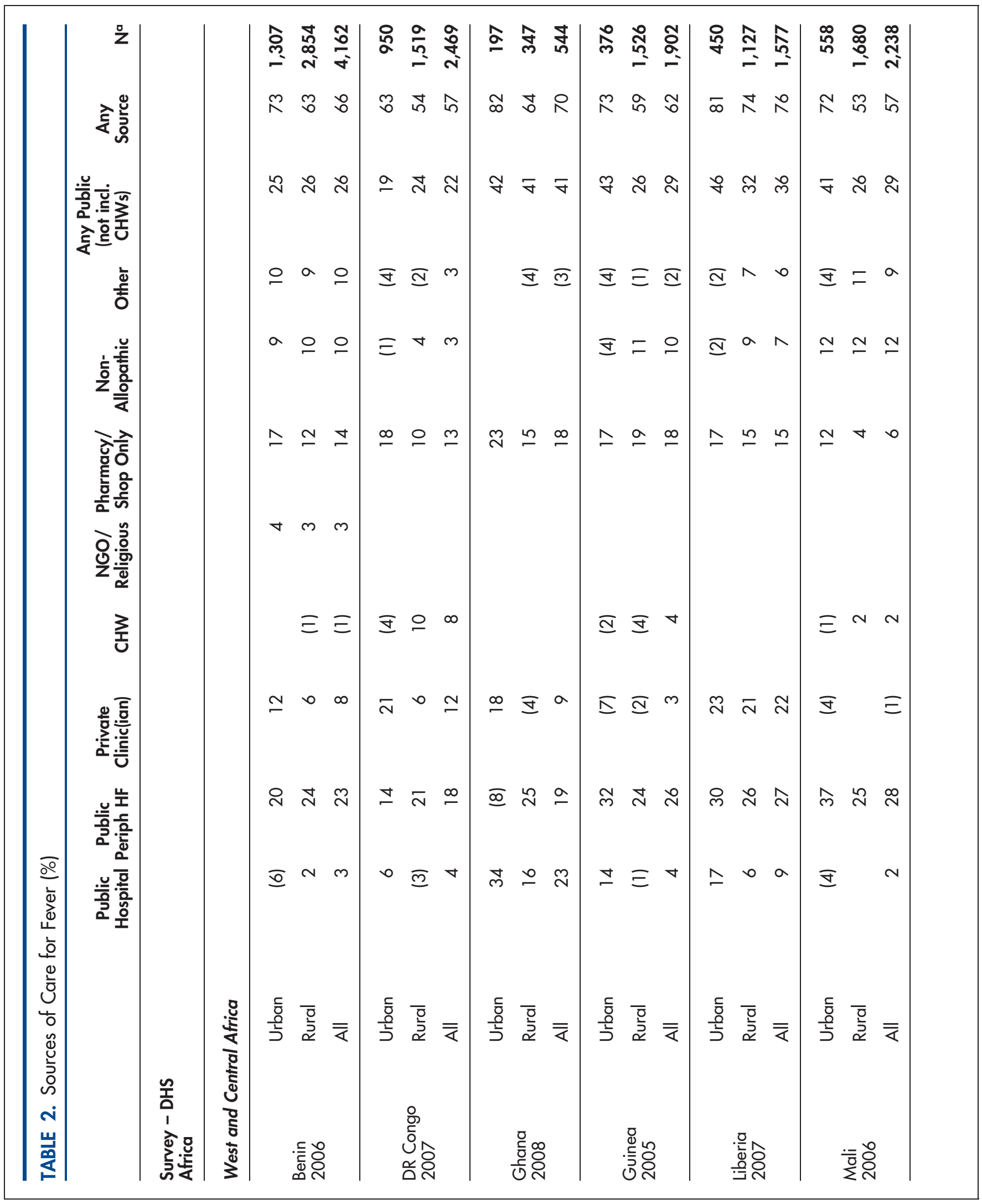




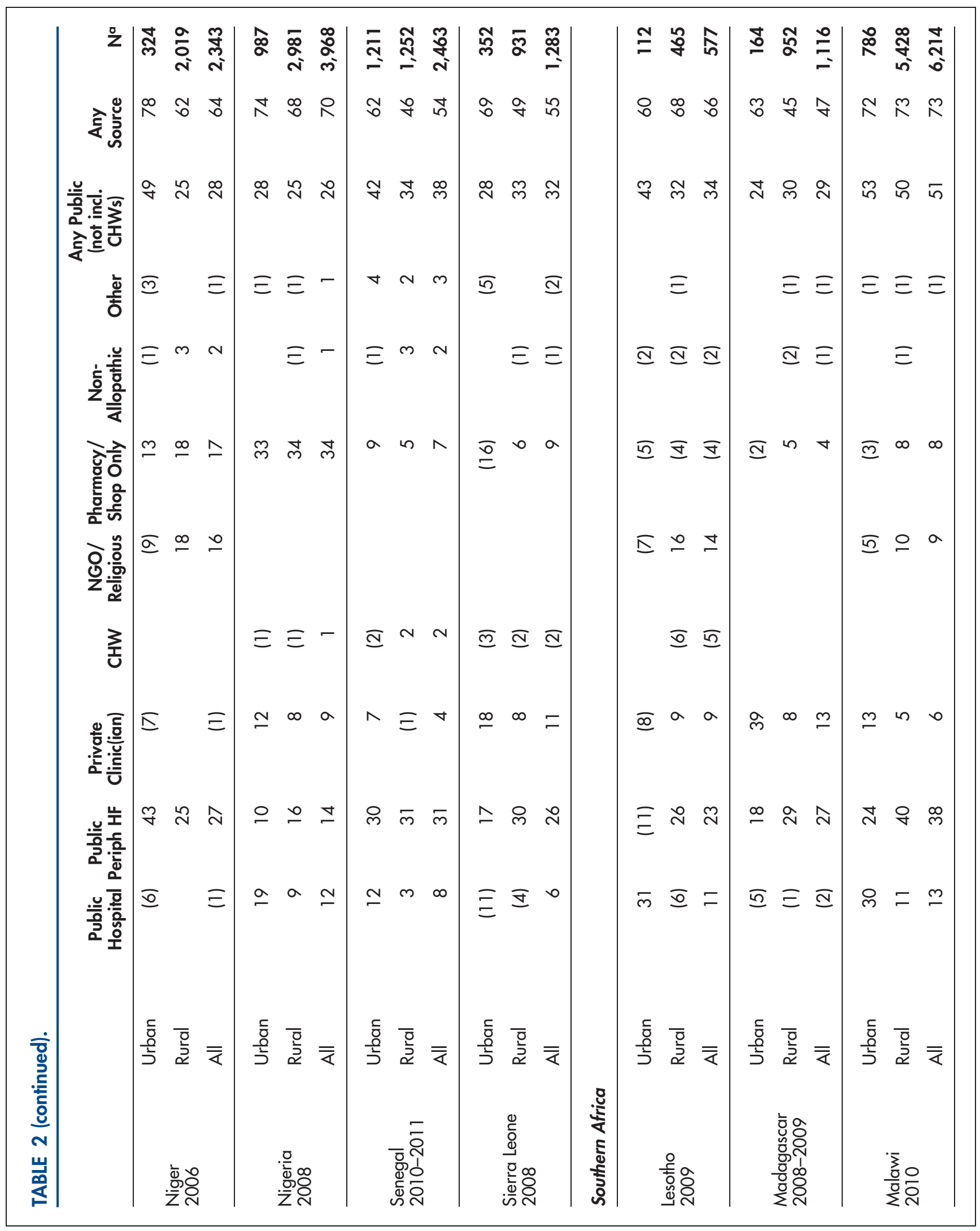




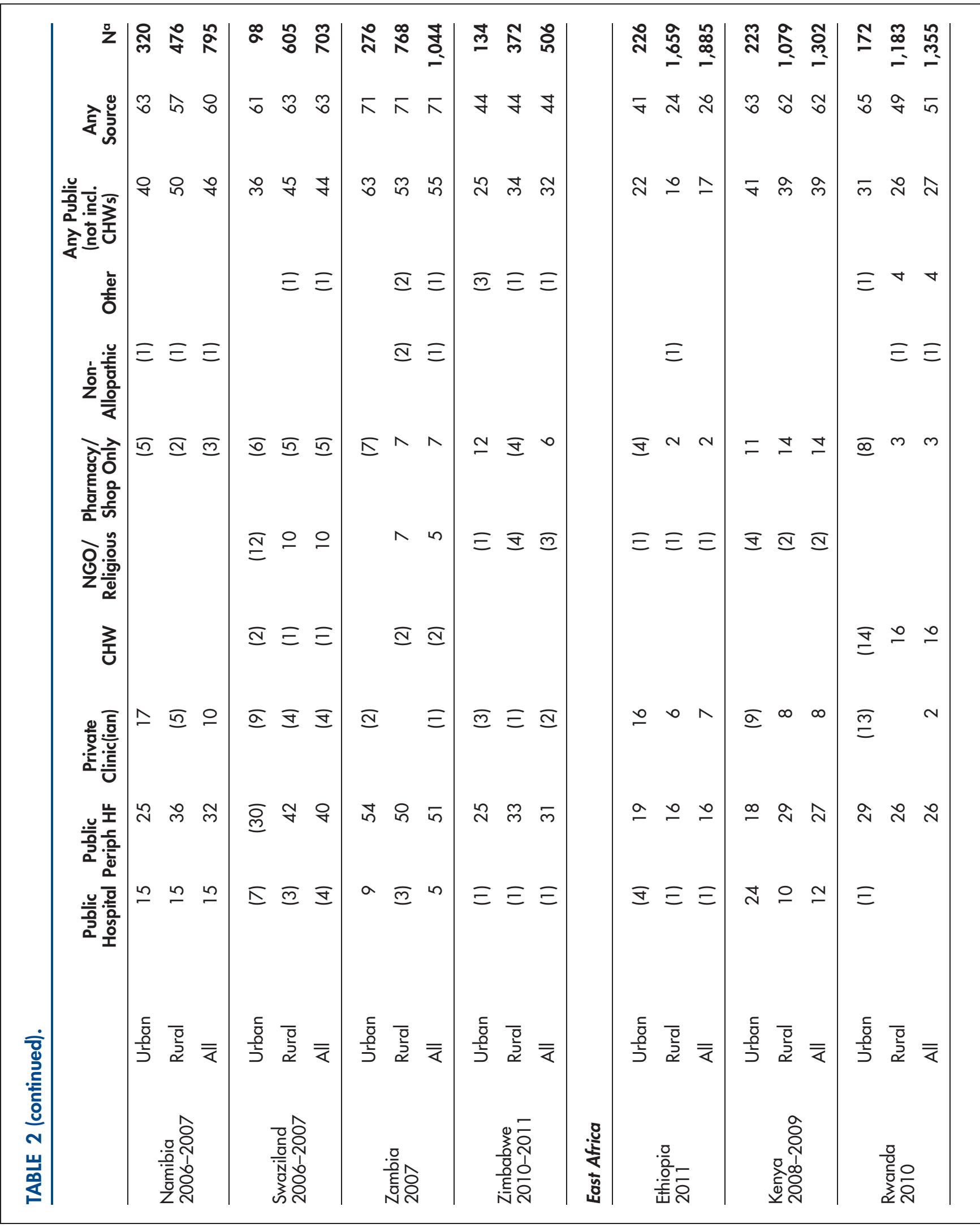




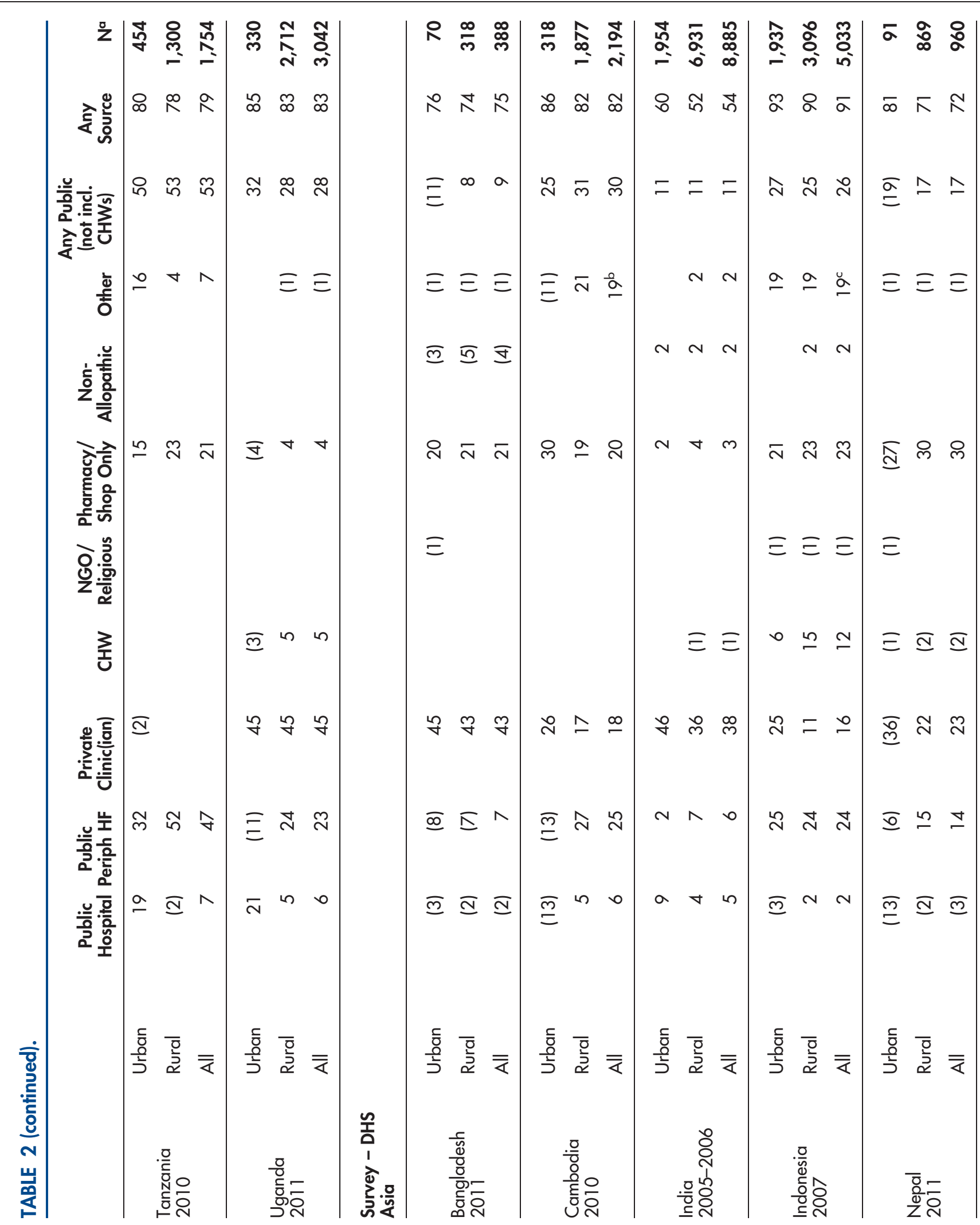




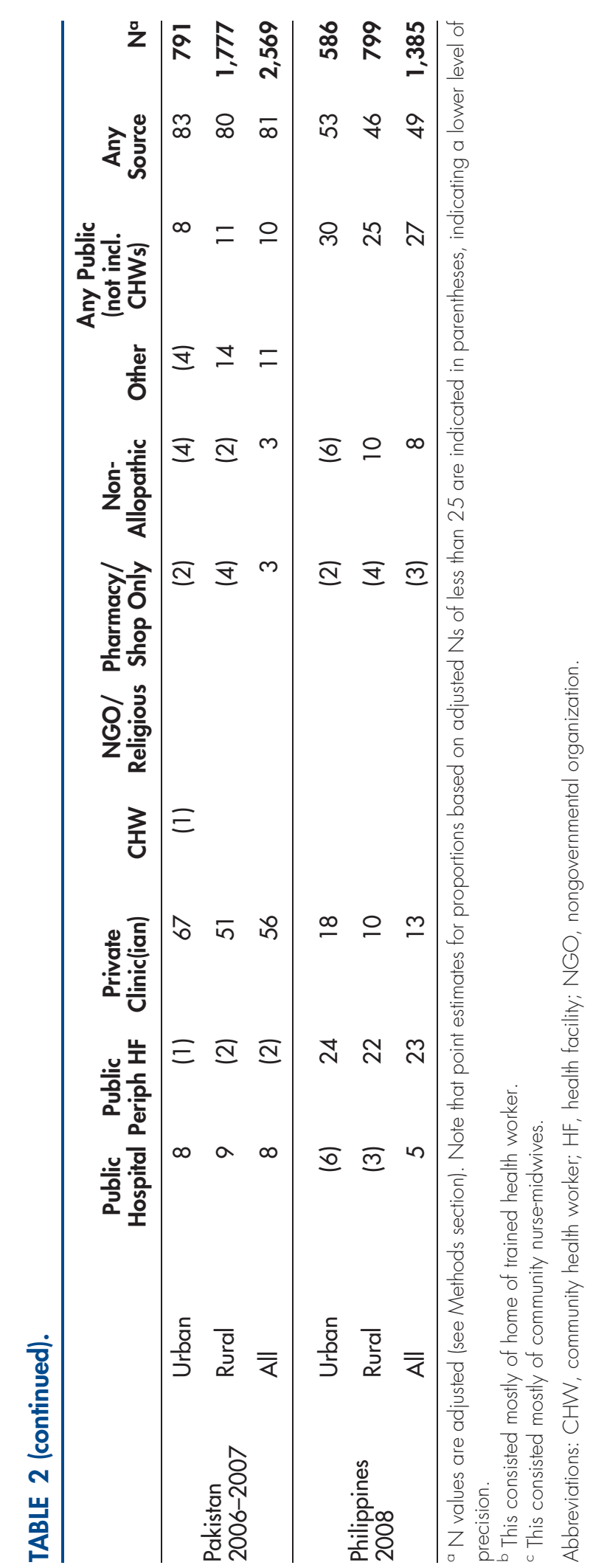




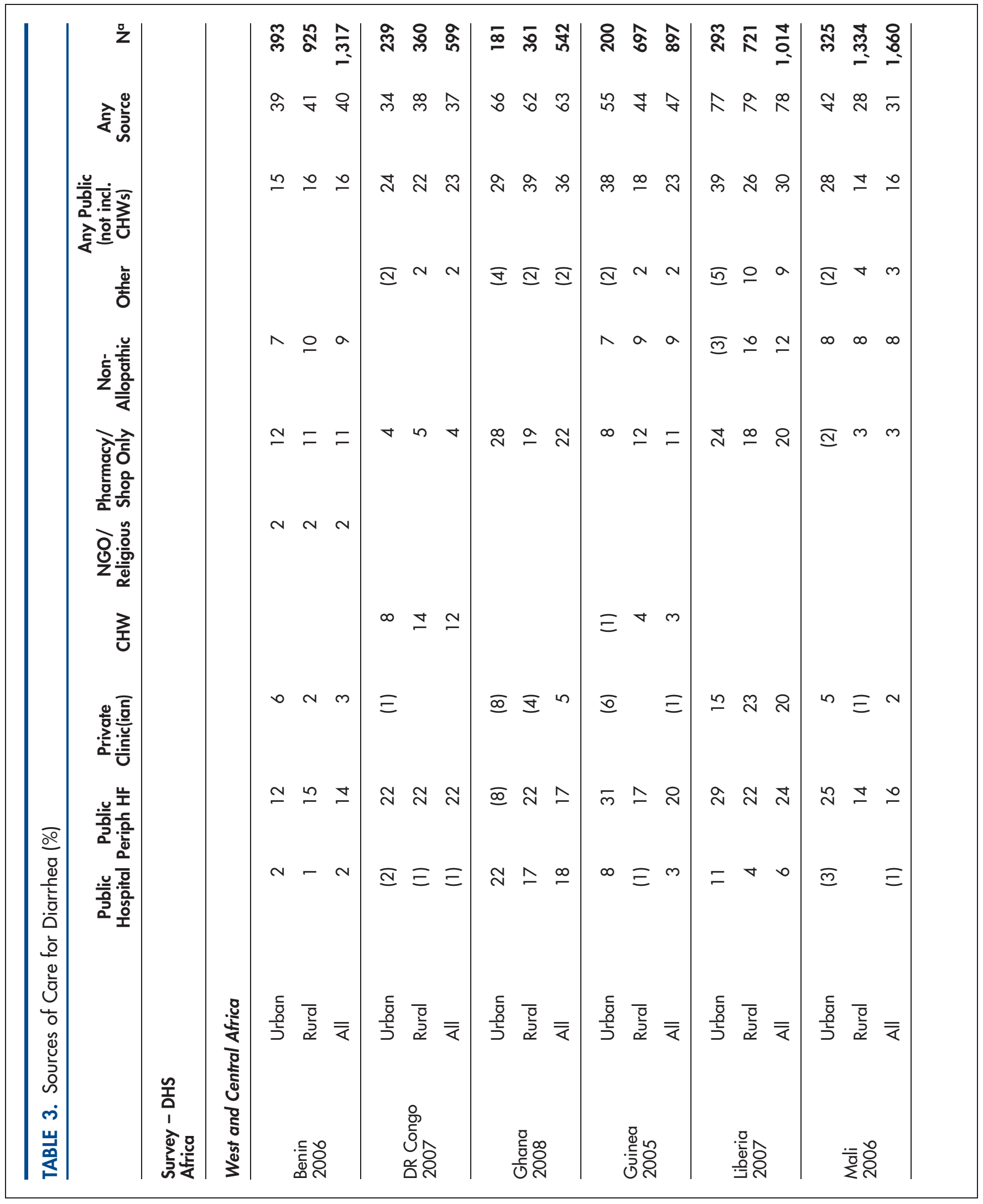




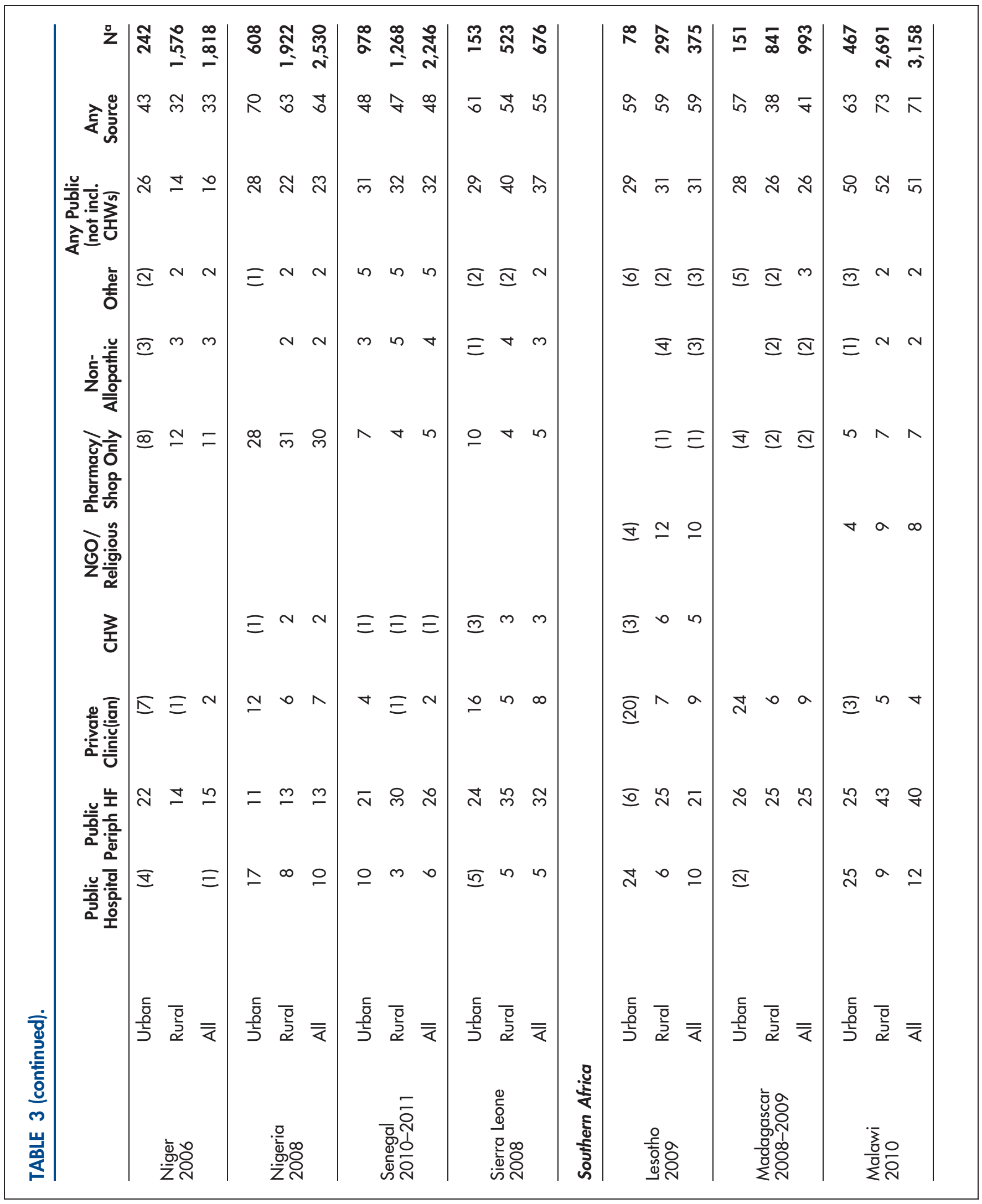




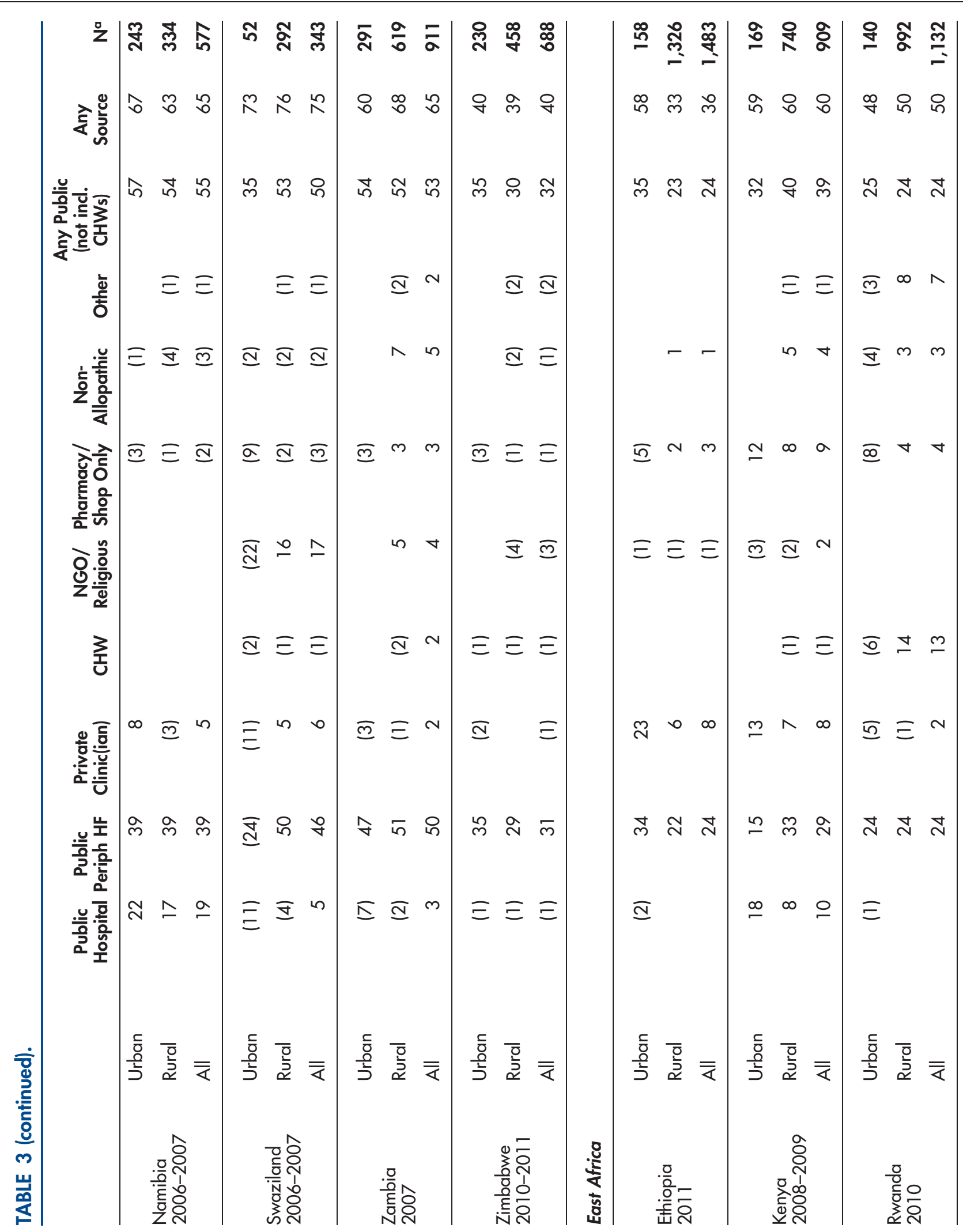




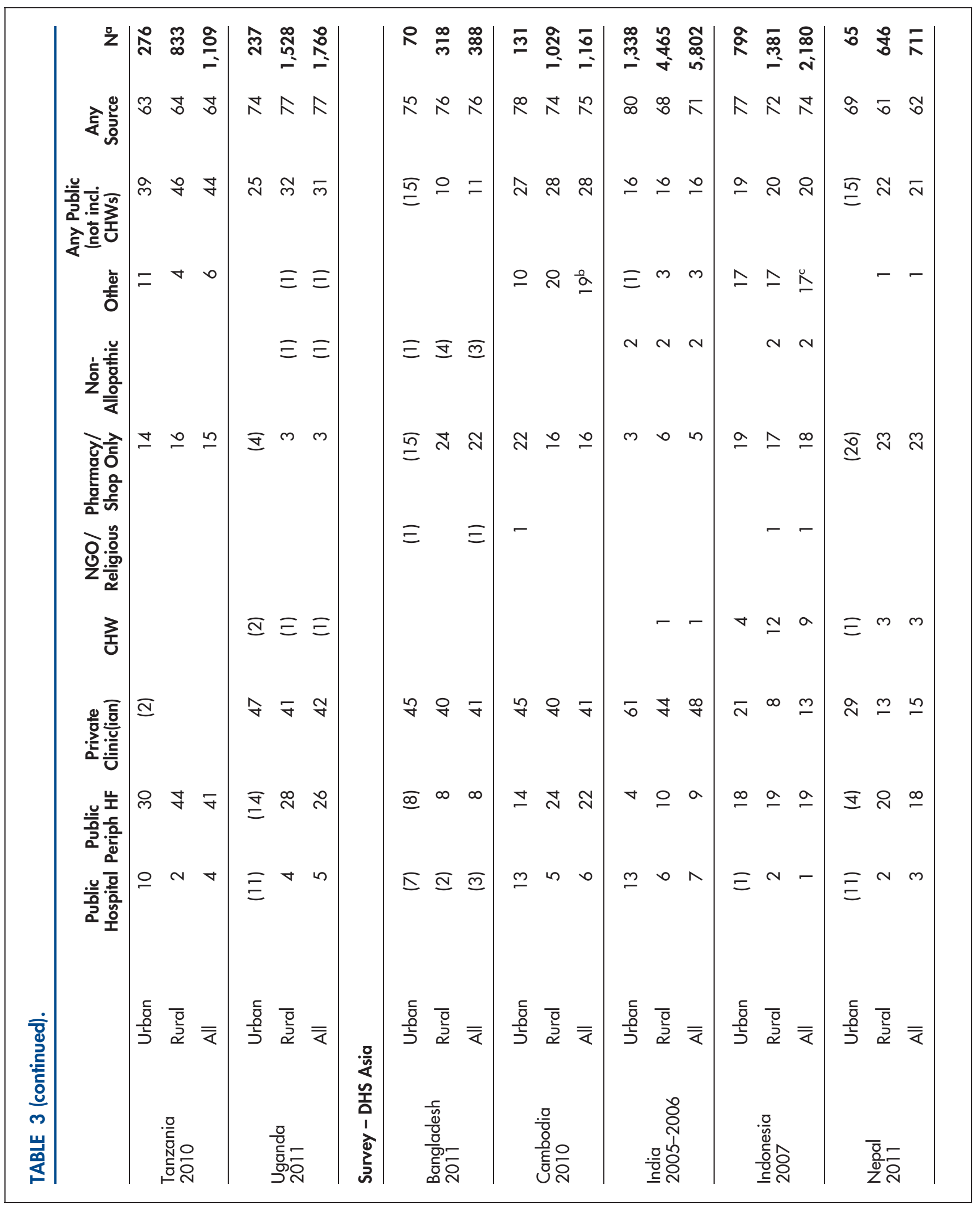




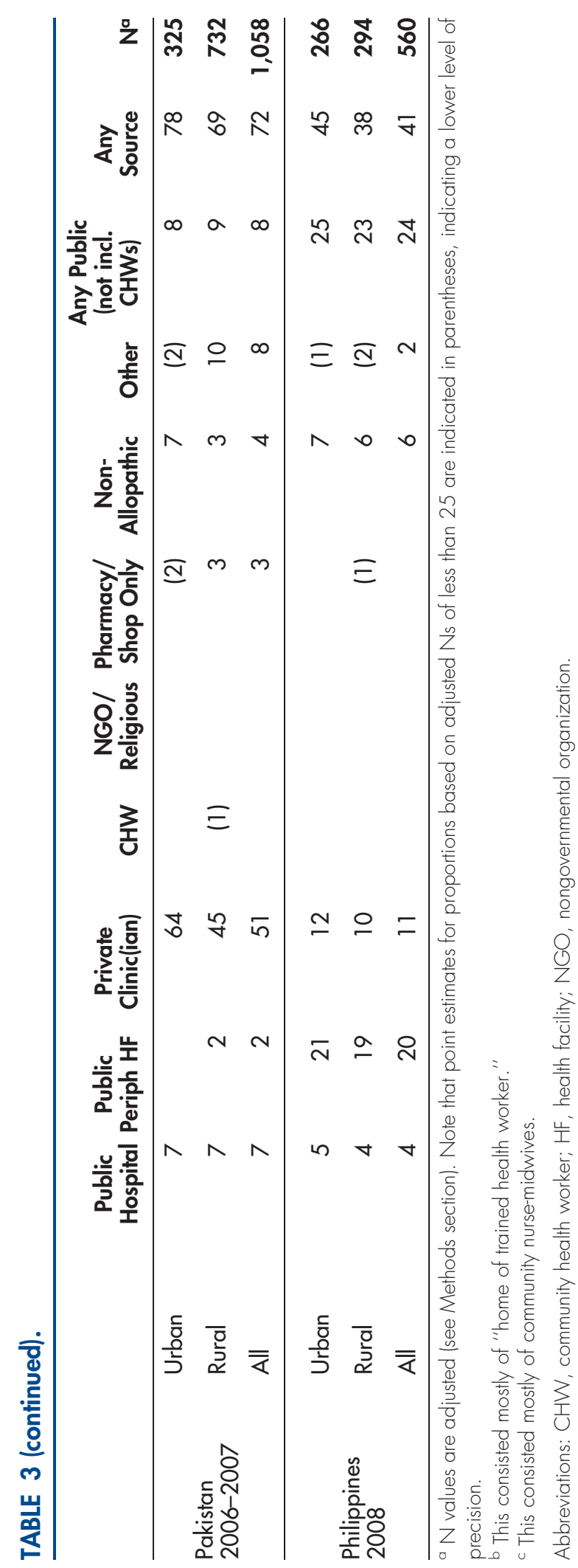


TABLE 4. Quality of ARI Care by "Received Antibiotics" (\%)

\begin{tabular}{|c|c|c|c|c|c|}
\hline \multirow[b]{2}{*}{ Survey } & & \multicolumn{2}{|c|}{ "Appropriate" provider } & \multicolumn{2}{|c|}{ "Non-appropriate" provider } \\
\hline & & Sought care (A) & $\begin{array}{l}\text { Received antibiotic } \\
\text { (as a \% of } A \text { ) }\end{array}$ & Sought care (B) & $\begin{array}{l}\text { Received antibiotic } \\
\text { (as a } \% \text { of B) }\end{array}$ \\
\hline \multicolumn{6}{|l|}{ Africa } \\
\hline Ethiopia & 2011 & 27 & 70 & 2 & (60) \\
\hline Ghana & 2008 & 51 & 35 & 14 & (16) \\
\hline Rwanda & 2010 & 50 & 74 & 12 & $(28)$ \\
\hline Senegal & $2010-2011$ & 50 & 50 & 10 & $(26)$ \\
\hline Swaziland & 2010 & 73 & 21 & 5 & 0 \\
\hline Uganda & 2011 & 79 & 54 & 5 & (49) \\
\hline Zimbabwe & $2010-2011$ & 48 & 47 & 7 & 51 \\
\hline \multicolumn{6}{|l|}{ Asia } \\
\hline Bangladesh & 2011 & 35 & 83 & 47 & 79 \\
\hline Nepal & 2011 & 48 & 37 & 29 & 61 \\
\hline
\end{tabular}

Values in parentheses are based on cell sizes of less than 25. 
TABLE 5. Quality of Diarrhea Care by "Appropriate" vs. "Non-Appropriate" Provider (\%)

\begin{tabular}{lllll}
\hline & \multicolumn{2}{c}{ "Appropriate" Provider } & \multicolumn{2}{c}{ "Non-Appropriate" Provider } \\
\cline { 2 - 5 } Survey & $\begin{array}{c}\text { Pills/syrups for non- } \\
\text { bloody diarrhea }\end{array}$ & ORS & $\begin{array}{c}\text { Pills/syrups for non- } \\
\text { bloody diarrhea }\end{array}$ & ORS \\
\hline
\end{tabular}

West and Central Africa

Benin 2006

DR Congo 2007

Ghana 2008

Guinea 2005

Liberia 2007

Mali 2006

Niger 2006

Nigeria 2008

Senegal 2010-2011

Sierra Leone $\quad 2008$

63

14

\section{7}

- 48

70

43

56

68

68

34

73

50

53

62

51

68

47

75

84

62

75

(44)

(10)

Madagascar

2008-2009

73

Malawi

2010

49

43

61

8

Namibia

2006-2007

83

44

61

Swaziland

2006-2007

36

87

61

94

Zimbabwe

2010-2011

45

(69)

Zambia

2007

86

67

26

\section{East Africa}

Ethiopia

2011

50

62

Kenya

2008-2009

54

Rwanda

2010

87

52

72

Tanzania

2010

62

64

66

64

57

67

45

Uganda

2011

65

54

58

29

Asia

$\begin{array}{ll}\text { Bangladesh } & 2011 \\ \text { Cambodia } & 2010 \\ \text { India } & 2005-2006 \\ \text { Indonesia } & 2007 \\ \text { Nepal } & 2011\end{array}$

$\begin{array}{ll}- & 87 \\ 62 & 50 \\ 65 & 36 \\ 74 & 56 \\ 48 & 63\end{array}$

63

-
73
67
80
66


TABLE 5 (continued).

\begin{tabular}{lccccc}
\hline & \multicolumn{2}{c}{ "Appropriate" Provider } & \multicolumn{2}{c}{ "Non-Appropriate" Provider } \\
\cline { 3 - 6 } Survey & $\begin{array}{c}\text { Pills/syrups for non- } \\
\text { bloody diarrhea }\end{array}$ & ORS & $\begin{array}{c}\text { Pills/syrups for non- } \\
\text { bloody diarrhea }\end{array}$ & ORS \\
\hline Pakistan & $2006-2007$ & 65 & 56 & 61 & 37 \\
Philippines & 2008 & 45 & 76 & (37) & $(54)$ \\
\hline
\end{tabular}

Values in parentheses are based on cell sizes of less than 25

" $"$ is indicated for surveys for which a general question on types of treatment received for diarrhea was not asked.

Abbreviations: ORS, oral rehydration solution.

BOX 1. Nepal (DHS 2011)

Care seeking for ARI is high, particularly in Nepal's urban areas, with advice or treatment sought for close to $80 \%$ of cases (pneumonia is the leading cause of death among children under 5, beyond the newborn period, with diarrhea also an important cause but malaria not accounting for a significant proportion of deaths). ${ }^{9}$ Children are twice as likely to receive care in the private as in the public sector. This is the case in both urban and rural settings; however, whereas private health workers are more commonly cited as a source of care in urban areas, retail outlets and private health workers are used at similar levels in rural areas. Although not apparent from these data, other research ${ }^{5}$ has documented that in most instances when it is reported that care is sought from a shop, some assessment is made by a health worker at the shop before dispensing treatment, so they are in effect functioning as private clinics. Nepal has a well-established CCM program for childhood illness; however, the DHS data suggest that CHWs do not make up a significant fraction of the case-provision mix (and reported recourse to care from this source has declined since the 2006 DHS). Care seeking for fever shows a similar pattern to that for ARI, with a high level of care seeking, particularly in urban settings, and the private sector as the primary source. For diarrhea, care seeking is at a somewhat lower level overall and is lower in rural than in urban areas. As with ARI, the private sector is the most important source of care for diarrhea, particularly in urban areas.

Among those seeking care for diarrhea from "appropriate" or medically qualified providers, almost two-thirds reported receiving ORS versus a little under half among those seeking care from "non-appropriate" providers. "Appropriate" providers dispensed pills or syrups for half the cases of non-bloody diarrhea seen; two-thirds of cases seen by nonappropriate providers received pills or syrups. For ARI, those seeking care from "appropriate" providers were less likely to report receiving antibiotics than in most of the other countries for which we have data. However, most ARI care from "non-appropriate" providers included provision of antibiotics.

Implications for Program Strategy: Although the public sector is a significant source of care, it plays a considerably smaller role than the private sector. Thus, to improve population health outcomes, efforts are warranted to identify and address gaps in the appropriateness and quality of care provided in the private sector. Antibiotic use by "appropriate providers" for ARI cases seen was relatively (perhaps inappropriately) low in comparison with that in other countries. Although the overall national picture shows relatively high levels of care seeking and a modest role for the public sector, there may be sub-populations or geographic areas showing quite different patterns. In these cases, a strategy focused on improving the coverage and quality of public sector provision (including use of community health workers) may still be appropriate. 
BOX 2. Ethiopia (DHS 2011)

Ethiopia has very low levels of care seeking for all 3 conditions (the lowest of the 29 countries analyzed by DHS in this paper for ARI and fever, and among the lowest for diarrhea), particularly in rural areas. Despite very low care seeking, under-5 mortality is lower than in many of the other African countries in this analysis. Those children who do get care are likely, in the case of ARI, to receive antibiotics, and, in the case of diarrhea, to receive ORS (although other pills and syrups are also commonly given). Private-sector care in Ethiopia is provided by health professionals (not at shops). For ARI, care is twice as likely to be sought from the public sector than from the private. This is also true for fever and diarrhea, although the private sector plays a slightly more important role than for ARI. Pneumonia is the leading cause of death among children under 5 beyond the newborn period ${ }^{10}$ and therefore is an appropriate focus for program effort. Malaria does not account for a significant proportion of deaths.

Implications for Program Strategy: With very low overall coverage and a minor role for the private sector, increasing coverage will require extending the public sector's reach more deeply at the community and household levels, particularly in rural areas, where most of the population lives. Although not reflected in the data presented here, this is the intent behind recent moves to increase sick-child care provided by health extension workers.

\section{BOX 3. Mali (DHS 2006)}

Mali continues to have very high under-5 mortality. At the time of the last DHS (2006), care seeking for ARI was at a moderate level and primarily from peripheral-level public-sector health facilities, although non-allopathic providers and drug shops were also significant sources of care. Care seeking for fever was comparatively low, with a wide gap between urban and rural coverage. This is notable, given high malaria mortality. Care for fever was sought predominantly from the public sector, although in urban areas some care was sought from retail outlets. Non-allopathic practitioners were a relatively important source of care for fever. Care seeking for diarrhea was lower than for any other country analyzed, with marked rural-urban disparity, and ORS use was very low. Non-allopathic practitioners were also consulted, although less frequently than for fever. Malaria, pneumonia, and diarrhea account for similar proportions of deaths among children under 5 beyond the newborn period, ${ }^{11}$ so all 3 warrant serious program attention.

Implications for Program Strategy: Coverage was very low for diarrhea; rural areas, in particular, were not well reached. Since use of the private sector is low, it would be important to extend peripheral public health services more effectively at the community and household levels in order to achieve better population health outcomes (noting that, along with Somalia and Sierra Leone, Mali has the highest under-5 mortality ${ }^{12}$ of the 42 countries included in this analysis). Current efforts to expand access through a new cadre of community health workers appear to be an appropriate response in this situation. The relatively high use of traditional practitioners indicates that consideration could be given to working with this group to improve access to, for example, oral rehydration solution. 
BOX 4. Uganda (DHS 2011)

Uganda is the one African country included in this analysis that showed a pattern of care seeking similar to that found in South Asia, relying primarily on private clinicians. For all 3 conditions, the proportion of cases of illness for which care was sought was high, and this was predominantly from "appropriate" providers, mainly private clinicians. Uganda was unusual among the countries included in this analysis in that in rural areas levels of care seeking were just as high as in urban areas, and, indeed, cases in rural areas were just as likely to be seen by private clinicians as in urban areas. Despite high levels of care seeking, child mortality is comparatively high. Quality of care appears to be an issue for diarrhea, as most cases of non-bloody diarrhea were treated with pills or syrups and fewer were given ORS. For ARI, slightly over half of those seen by "appropriate" providers reported having received antibiotics; this level may be compatible with appropriate use of antibiotics. Pneumonia is the number one cause of death among children under 5, beyond the newborn period, although malaria and diarrhea are also important causes. ${ }^{13}$

Implications for Program Strategy: Based on this analysis, access to services is less of a problem in Uganda than in the other countries considered. Care is primarily provided in the private sector, by presumably medically qualified practitioners. However, this analysis suggests problems of quality of care, with too little use of ORS for diarrhea and inappropriate use of other remedies for non-bloody diarrhea. Accordingly, it would be appropriate for program efforts to be directed at improving quality of care given by private-sector providers of sick-child care, notably for diarrhea. All 3 of the major childhood conditions considered here are important causes of death and warrant serious program effort.

BOX 5. Senegal (DHS 2010-11)

Compared with rates in other countries in West Africa, under-5 mortality in Senegal is comparatively low. ${ }^{14}$ Malaria is the leading cause, followed by pneumonia and diarrhea. ${ }^{15}$ Care seeking from any source was lower than in most other countries considered here across all 3 categories of childhood illnesses. For ARI and fever, care seeking is somewhat lower in rural areas than in urban. Care-seekers relied primarily on public-sector providers, and non-medically qualified providers were not an important source. Senegal was one of the first countries in Africa to adopt and scale up management of childhood illness by community health workers (that is, CCM). By the time of the last DHS survey, this program had been implemented in 58 of the 69 districts in the country (personal communication with Serge Raharison). It is surprising, therefore, that for none of the 3 conditions are community health workers reported to have provided care for more than $2 \%$ of cases.

Oral rehydration salts were dispensed less frequently than in most other countries considered. Prescribing various pills and syrups was more common. Half of cases of ARI for which a medically qualified provider was consulted received antibiotics.

Implications for Program Strategy: Since the private sector is not playing a prominent role in service provision, it would be sensible to focus program efforts on public-sector provision. The recent effort to expand access would seem appropriate given that care from any source has been lower than in many other countries (including some of Senegal's neighbors). However, the continued overall low level of care seeking and the very infrequent recourse to community health workers as a source of care suggests that there have been significant implementation problems with CCM. It would be warranted to investigate the factors that have contributed to the apparently poor performance of this program (such as availability of program commodities and acceptability of the providers) as well as the most significant barriers to obtaining care from public-sector health facilities. The relatively low rate of ORS dispensing also needs to be addressed. 
Acknowledgments: This study was carried out with support provided by the U.S. Agency for International Development (USAID) through the MEASURE DHS project (\#GPO-C-00-08-00008-00).

Competing Interests: None declared.

\section{REFERENCES}

1. Liu L, Johnson HL, Cousens S, Perin J, Scott S, Lawn JE, et al. Global, regional, and national causes of child mortality: an updated systematic analysis for 2010 with time trends since 2000. Lancet. 2012;379(9832):2151-2161. CrossRef. Medline

2. Goldman N, Pebley AR, Gragnolati M. Choices about treatment for ARI and diarrhea in rural Guatemala. Soc Sci Med. 2002;55(10):1693-1712. CrossRef. Medline

3. Larson CP, Saha UR, Islam R, Roy N. Childhood diarrhoea management practices in Bangladesh: private sector dominance and continued inequities in care. Int J Epidemiol. 2006;35(6):1430-1439. CrossRef

4. Najnin N, Bennett CM, Luby SP. Inequalities in care-seeking for febrile illness of under-five children in urban Dhaka, Bangladesh. J Health Popul Nutr. 2011 ;29(5):523-531. CrossRef. Medline

5. Quinley J, Govindasamy P. The treatment of childhood illness in Nepal: further analysis of the $2006 \mathrm{Nepal} \mathrm{Demographic} \mathrm{and}$ Health Survey. Calverton, Maryland, USA: Macro International; 2007. Available from: http://www.measuredhs.com/pubs/ pdf/FA49/FA49.pdf

6. Boschi-Pinto C, Bahl R, Martines J. Limited progress in increasing coverage of neonatal and child-health interventions in Africa and Asia. J Health Popul Nutr. 2009;27(6):755-762. Medline

7. Montagu D. Private healthcare in developing countries [Internet]. San Francisco, CA: Private healthcare in developing countries; c2008 [cited 2013 Oct 31]. Available from: http://www.ps4h. org/

8. Awor P, Wamani H, Bwire G, Jagoe G, Peterson S. Private sector drug shops in integrated community case management of malaria, pneumonia, and diarrhea in children in Uganda. Am J Trop Med Hyg. 2012;87(5)(Suppl):92-96. Medline

9. World Health Organization (WHO), UNICEF. Countdown to 2015: maternal, newborn \& child survival. Building a future for women and children: the 2012 report. Nepal country profile. Geneva: WHO; 2012. Available from: http://www. countdown2015mnch.org/documents/2012Report/2012/ 2012_Nepal.pdf

10. World Health Organization (WHO), UNICEF. Countdown to 2015: maternal, newborn \& child survival. Building a future for women and children: the 2012 report. Ethiopia country profile. Geneva: WHO; 2012. Available from: http://www. countdown2015mnch.org/documents/2012Report/2012/ 2012_Ethiopia.pdf

11. World Health Organization (WHO), UNICEF. Countdown to 2015: maternal, newborn \& child survival. Building a future for women and children: the 2012 report. Mali country profile. Geneva: WHO; 2012. Available from: http://www. countdown2015mnch.org/documents/2012Report/2012/ 2012_Mali.pdf

12. World Health Organization (WHO), UNICEF. Countdown to 2015: maternal, newborn \& child survival. Building a future for women and children: the 2012 report. Geneva: WHO; 2012. Available from: http://www.countdown2015mnch.org/reports-andarticles/2012-report

13. World Health Organization (WHO), UNICEF. Countdown to 2015: maternal, newborn \& child survival. Building a future for women and children: the 2012 report. Uganda country profile. Geneva: WHO; 2012. Available from: http://www. countdown2015mnch.org/documents/2012Report/2012/ 2012_Uganda.pdf

14. United Nations Inter-agency Group for Child Mortality Estimation. Levels and trends in child mortality: report 2012. New York: UNICEF; 2012. Available from: http:// apromiserenewed.org/files/UNICEF_2012_child_mortality_for_ web_0904.pdf

15. World Health Organization (WHO), UNICEF. Countdown to 2015: maternal, newborn \& child survival. Building a future for women and children: the 2012 report. Senegal country profile. Geneva: WHO; 2012. Available from: http://www. countdown2015mnch.org/documents/2012Report/2012/ 2012_Senegal.pdf

\section{Peer Reviewed}

Received: 2013 Mar 8; Accepted: 2013 Jul 17; First Published Online: 2013 Nov 8

Cite this article as: Hodgins S, Pullum T, Dougherty L. Understanding where parents take their sick children and why it matters: a multi-country analysis. Glob Health Sci Pract. 2013;1(3):328-358. http://dx.doi.org/10.9745/GHSP-D-13-00023

(c) Hodgins et al. This is an open-access article distributed under the terms of the Creative Commons Attribution License, which permits unrestricted use, distribution, and reproduction in any medium, provided the original author and source are properly cited. To view a copy of the license, visit http://creativecommons.org/licenses/by/3.0/ 